\title{
Cluster model DFT study of lactic acid dehydration over Fe and Sn-BEA zeolite
}

\author{
Izabela Czekaj $^{\mathbf{a}^{*}}$ and Natalia Sobuś ${ }^{\mathrm{a}}$
}

\begin{tabular}{|c|c|}
\hline C H R O N I C L E & A B S T R A C T \\
\hline $\begin{array}{l}\text { Article history: } \\
\text { Received March 17, } 2019 \\
\text { Received in revised form } \\
\text { May 20, } 2019 \\
\text { Accepted May 28, } 2019 \\
\text { Available online } \\
\text { May 30, } 2019 \\
\end{array}$ & \multirow{2}{*}{$\begin{array}{l}\text { This paper is interested in mechanism of lactic acid (LA) adsorption and dehydration into } \\
\text { acrylic acid (AA) over tin and iron beta zeolite ( } \mathrm{Sn} \text { - and Fe-BEA) catalysts. The electronic } \\
\text { structure of clusters was calculated by ab initio density functional theory (DFT) method. The } \\
\mathrm{M}_{2} \mathrm{Si}_{12} \mathrm{O}_{39} \mathrm{H}_{22} \text { (hierarchical zeolite) and } \mathrm{M}_{2} \mathrm{Si}_{22} \mathrm{O}_{64} \mathrm{H}_{32} \text { (ideal zeolite) clusters (M=Al, Si, Sn) } \\
\text { were used in the LA dehydration reaction. The stabilization of the dimeric complex M-Ob-M } \\
\text { (where } \mathrm{M}=\mathrm{Sn} \text { or Fe) in the BEA, ideal and hierarchical structure, was investigated. Possible } \\
\text { modes of interaction of lactic acid with different cations ( } \mathrm{Si}, \mathrm{Al} \text {, Fe or Sn) in the BEA zeolite } \\
\text { framework as well as with added iron and tin dimers were considered. The interaction of lactic } \\
\text { acid was only observed above the } \mathrm{M}-\mathrm{O}_{\mathrm{b}}-\mathrm{M} \text { dimer. The direct mechanism of lactic acid } \\
\text { dehydration into acrylic acid was found over metal M-Ob-M dimers deposited at the BEA } \\
\text { zeolite. }\end{array}$} \\
\hline $\begin{array}{l}\text { Keywords: } \\
\text { Lactic acid } \\
\text { Acrylic acid } \\
\text { Beta zeolite } \\
\text { DFT }\end{array}$ & \\
\hline
\end{tabular}

Dehydration

Biomass

\section{Introduction}

The urgent need for more sustainable production of chemicals from renewable feedstock, like biomass, have resulted in intensive research efforts in the search for novel porous nano-materials. ${ }^{1}$ Due to its ability to catalyze many types of hydrocarbon reactions and the specific structure of the active sites, zeolites are ideal candidates for the production of chemicals from biomass, e.g. dehydration reactions. ${ }^{2,3}$ Important properties of zeolites, which make them ideal candidates for the transformation of biomass into high value chemicals, are their high hydrothermal stabilities.

Metal substituted BEA and MFI have been the most studied zeolites, especially for reactions where Lewis acidity is required..$^{4-7}$ Many groups have already been investigated, such as zeolites substituted with tin and other metals. The activity of Sn-BEA in the conversions of glucose to fructose has been significant, while the same reaction has not been noted over $\mathrm{Sn}-\mathrm{MFI}{ }^{8}$ The other groups have correlated the adsorption of probe molecules, such as ammonia, acetonitrile, water or pyridine, with the Lewis acidity of M-BEA $(\mathrm{M}=\mathrm{Ti}, \mathrm{Zr}, \mathrm{Sn}),{ }^{9}$ and specifically $\mathrm{Sn}-\mathrm{BEA} .{ }^{10}$

Iron-exchanged zeolites (ZSM-5 and BEA) are an active catalyst for a large number of reactions, of which the selective catalytic reduction (SCR) of nitrogen oxides with ammonia or hydrocarbons, ${ }^{11-16}$ the $\mathrm{N}_{2} \mathrm{O}$ decomposition reaction ${ }^{17,18}$ and oxidation processes ${ }^{19-22}$ are the most important. The stabilization of dimeric Fe-O-Fe iron complexes in the ZSM-5 framework has been already investigated

* Corresponding author. Tel.: +48 (0)12 6282111

E-mail address: iczekaj@.chemia.pk.edu.pl (I. Czekaj)

(C) 2019 by the authors; licensee Growing Science, Canada doi: $10.5267 / \mathrm{j} . c c 1.2019 .005 .002$ 
using a DFT approach with a cluster model ${ }^{23}$ The Fe-BEA zeolite has also been studied theoretically for nitrous oxide decomposition along similar lines. ${ }^{24,25}$ However, the authors will only consider monomeric Fe.

The structure and exact role of the active iron sites in these different catalytic reactions are still the subject of many discussions. For the $\mathrm{SCR}$ of $\mathrm{NO}_{\mathrm{x}}$, different active iron sites, such as small oxygen bridged clusters [HO-Fe-O-Fe-OH] $]^{2+},{ }^{16,26-29}$ isolated $\mathrm{Fe}^{2+}$ and $\mathrm{Fe}^{3+}$ ions ${ }^{30,31}$ or extra-framework $\mathrm{Fe}-\mathrm{O}$ $\mathrm{Al}$ and grafted $\mathrm{Fe}-\mathrm{O}-\mathrm{Si}$ species ${ }^{32,33}$ have been suggested. Previous studies suggest that all of these iron species usually coexist in the pores of the ZSM-5 framework; binuclear iron and isolated iron species have been suggested as the active sites for the SCR reaction ${ }^{34-38}$.

Lactic acid has three available atoms for adsorption: the oxygen atom of the alcohol group and the two oxygen atoms of the carboxyl group. Based on the literature, ${ }^{39}$ the lactic acid adsorption over metallic cations gives several possible binding modes at zirconia surfaces: monodentate, bidentate bridging and bidentate chelating, where a dissociative bidentate bridging mode is preferred. The classical pathway through a carbocation proceeds with a very high activation energy. Therefore, the authors suggested another mechanism through a carbanion and succeeded with acrylic acid formation.

In the present study, we are interested in designing a new theoretical approach for the synthesis of acrylic acid (AA) from lactic acid (LA) over zeolite catalysts. The theoretical modeling of lactic acid dehydration helps in the further development and synthesis of zeolite with declare structure. Lactic acid adsorption and dehydration toward acrylic acid processes have been studied in BEA zeolite. The tin and iron dimers are considered in the present studies as active sites for lactic acid adsorption.

\section{Results and Discussion}

\subsection{Computational details}

The electronic structure of all clusters was calculated by ab initio density functional theory (DFT) methods (program StoBe) using the non-local generalized gradient corrected functionals according to Perdew, Burke, and Ernzerhof (RPBE), in order to account for electron exchange and correlation. The electronic structure of the clusters and of all reaction intermediates was calculated by $a b$ initio density functional theory (DFT) methods (StoBe code). ${ }^{40}$ The generalized gradient corrected functionals according to revised Perdew, Burke, and Ernzerhof (rPBE) were used in order to account for electron exchange and correlation. ${ }^{41,42}$ All Kohn-Sham orbitals are represented by linear combinations of atomic

orbitals (LCAO's) using extended contracted Gaussian basis sets for the atoms. ${ }^{43,44}$ A detailed analysis of the electronic structure of the clusters was carried out using Mulliken populations ${ }^{45}$ and Mayer bond order indices ${ }^{46,47}$. The adsorption energies of the adsorbates on the cluster were calculated as follows:

$\mathrm{E}_{\mathrm{ad}}($ adsorbate/cluster $)=\mathrm{E}_{\text {tot }}($ adsorbate/cluster $)-\mathrm{E}_{\text {tot }}($ cluster $)-\mathrm{E}_{\text {tot }}($ adsorbate $)$,

where $\mathrm{E}_{\text {tot }}$ (adsorbate/ cluster) is the total energy of the adsorbate/cluster surface complex, $\mathrm{E}_{\text {tot }}(\mathrm{cluster})$ and $\mathrm{E}_{\text {tot }}$ (adsorbate) are the total energies of pure cluster and the adsorbate, respectively.

A double zeta valence polarization (DZVP) type was used for the orbital basis sets of Sn (633321/53321/531), Fe (63321/531/311), Si (6321/521/1), Al (6321/521/1), O, C (621/41/1), and H (41). Auxiliary basis sets, such as $(5,5 ; 5,5)$ for $\mathrm{Si}$, Sn and Fe, $(4,3: 4,3)$ for $\mathrm{O}, \mathrm{C}, \mathrm{N}$, and (41) for $\mathrm{H}$, were applied to fit the electron density and the exchange-correlation potential.

\subsection{Geometrical model}

The crystal structure of BEA has been chosen from Database of Zeolite Structure. ${ }^{48}$ The tetragonal phase of BEA framework type, is described by the space group P 4122 (no. 91) with lattice constants $\mathrm{a}=\mathrm{b}=12.6320 \AA$ and $\mathrm{c}=26.1860 \AA$. The crystal unit cell contains 192 atoms. 
The BEA framework (purely siliceous silicalite-1 and aluminum-containing BEA) has a three dimensional channel system consisting of straight channels along the $a$ and $b$ axis and tortuous channel along the $c$-axis. ${ }^{49}$ The pore limiting diameter of largest pore is equal $6.9 \AA$ (Figure 1 ) ${ }^{50} \mathrm{~A}$ maximum sphere diameter that can diffuse along BEA pores is equal $5.95 \AA .{ }^{48}$

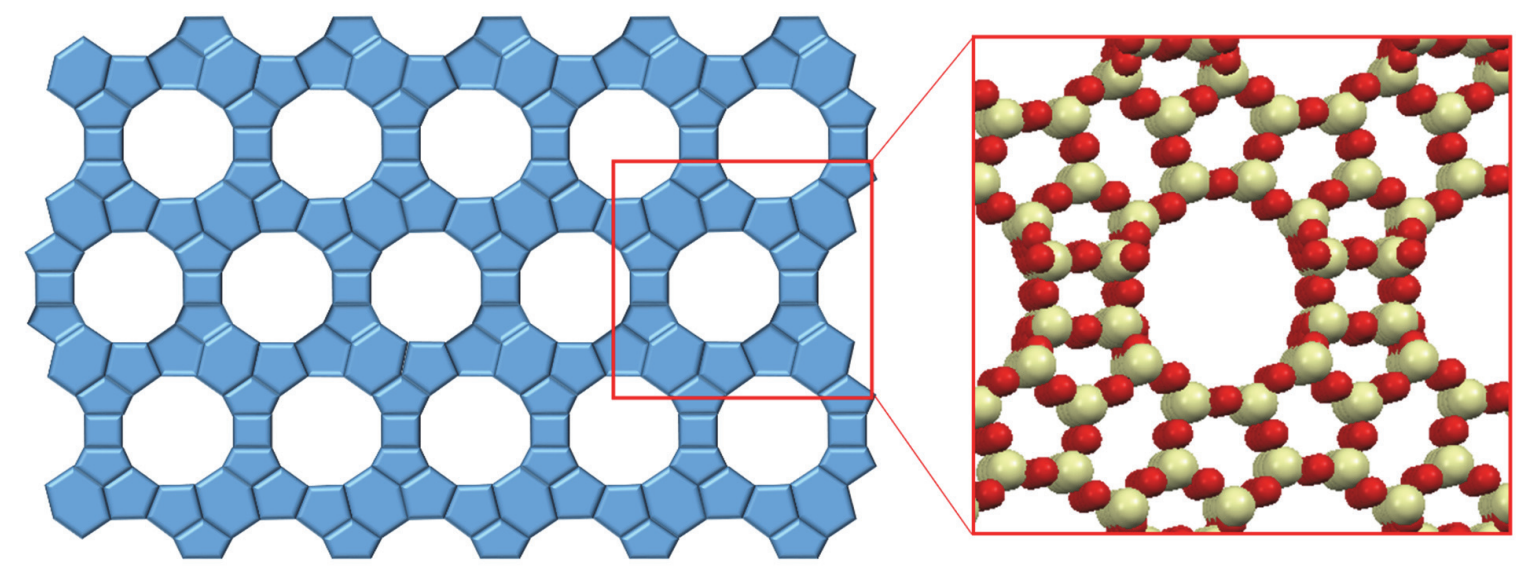

Fig. 1. BEA structure -projection along [100] direction. Blue structure represents Si-Si bonds

Several clusters, which represent BEA zeolite, have been analyzed and finally the $\mathrm{M}_{2} \mathrm{Si}_{22} \mathrm{O}_{64} \mathrm{H}_{32}$ (ideal) and $\mathrm{M}_{2} \mathrm{Si}_{12} \mathrm{O}_{39} \mathrm{H}_{22}$ (hierarchical) clusters $(\mathrm{M}=\mathrm{Al}$, Si, Sn, $\mathrm{Fe}$ ) have been used in LA dehydration reaction (Fig. 2). The ideal $\mathrm{M}_{2} \mathrm{Si}_{22} \mathrm{O}_{64} \mathrm{H}_{32}$ model shows the cage structure existing in the BEA zeolite (Fig. 2b), where hierarchical $\mathrm{M}_{2} \mathrm{Si}_{12} \mathrm{O}_{39} \mathrm{H}_{22}$ cluster includes half of such cage and could be present after hierarchization process, which is visualized at Fig. 2 b.
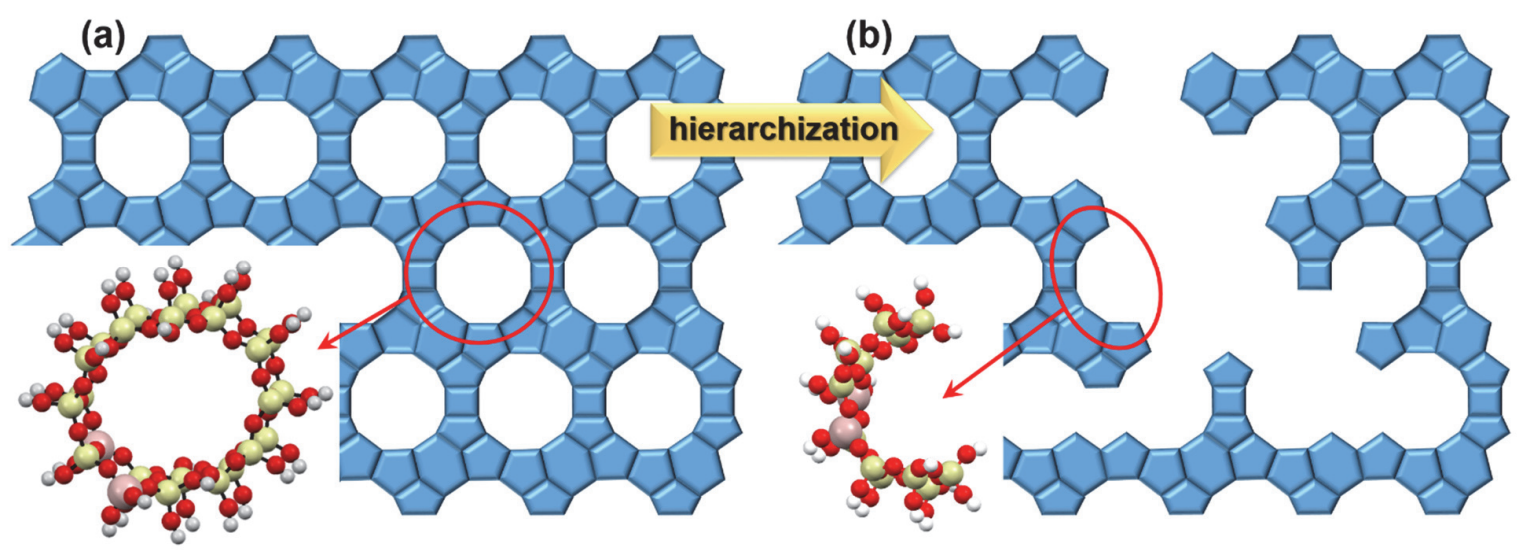

Fig. 2. Clusters representing BEA structure: (a) $\mathrm{M}_{2} \mathrm{Si}_{22} \mathrm{O}_{64} \mathrm{H}_{32}$ (ideal) and (b) $\mathrm{M}_{2} \mathrm{Si}_{12} \mathrm{O}_{39} \mathrm{H}_{22}$ (hierarchical) clusters $(\mathrm{M}=\mathrm{Al}, \mathrm{Si}, \mathrm{Sn})$. Blue structures represent $\mathrm{Si}-\mathrm{Si}$ bonds in BEA before and after hierarchization

The localization of aluminium cations has been chosen according to the previous findings, ${ }^{23}$ where the distance between Al-Al centers was around $5 \AA$. Distance between aluminium cations at chosen positions (Figure 3) in BEA frame is equal $4.98 \AA$. 

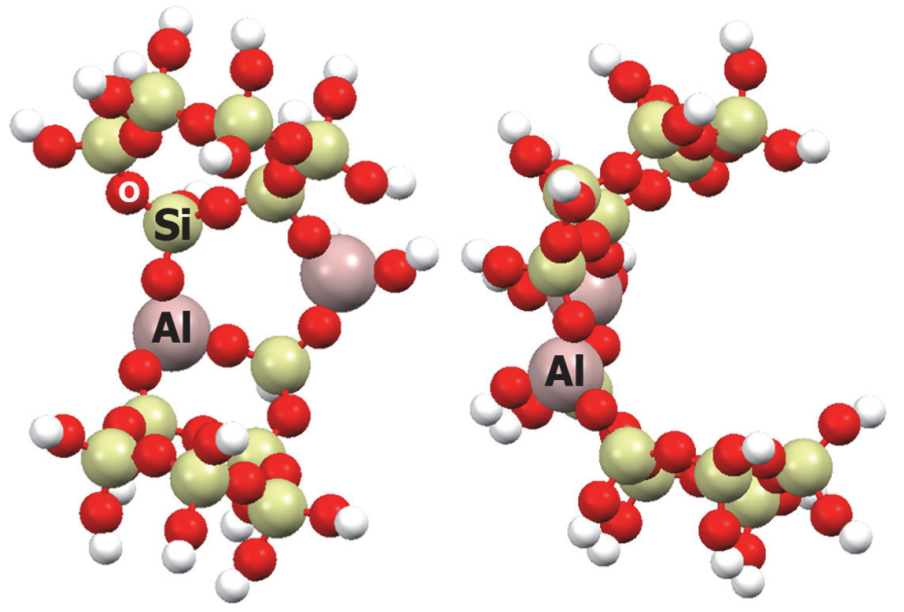

Fig. 3. Localization of Al cations in BEA frame

\subsection{Extra and intra metals in the BEA-framework}

Different modifications by metal cations are possible in BEA: (i) isomorphous substitution as intra metal species (where the Si or Al in the framework of zeolite is substituted by metals, e.g. Sn, Fe, Fig. $4 \mathrm{a}$ and b), (ii) grafting as extra metal species (where metals are grafted in the form of mono-, polymers or nanoparticles on the outer surface or in the inner pores of zeolite, Fig. 4 c-e). In the present study we considered both types of zeolite modifications, substituted metals as well as dimeric forms of metals grafted onto the zeolite framework.

To date, most of the theoretical groups substituted tin inside the zeolite framework. ${ }^{4-10}$ However, in the case of our studies, lactic acid was not stabilized above any zeolite frame-centers (neither $\mathrm{Si}, \mathrm{Al}$ nor $\mathrm{Sn}$ in positions presented at Fig. 4a-b). As the next step, the tin and iron dimers (Fig. 4d) were considered in the present study as active sites for lactic acid adsorption, which is a new approach compared to those mentioned previously in the literature, especially in the case of tin. ${ }^{6-10}$
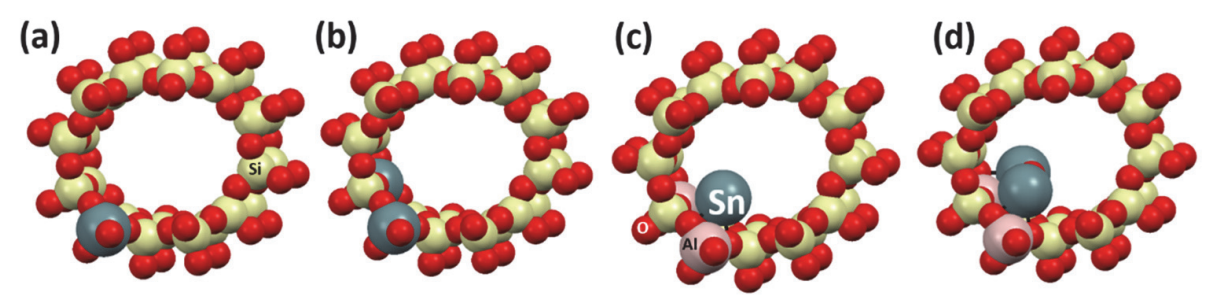

(e)

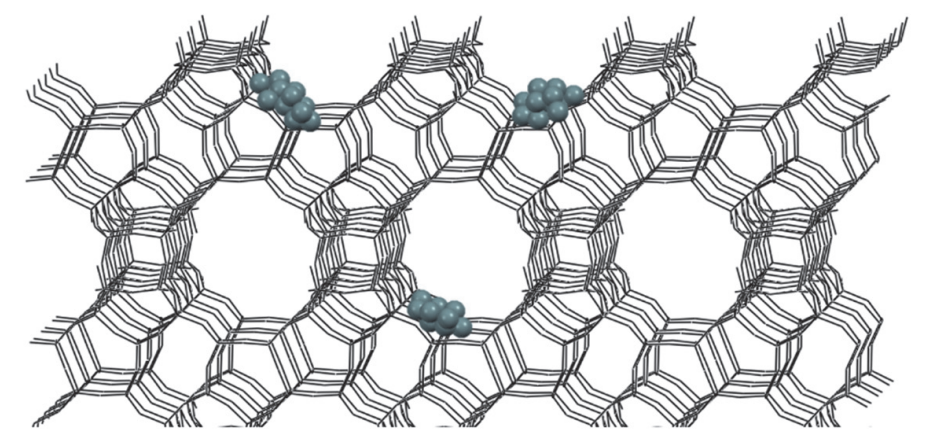

Fig. 4. Possible substitution of metal in the BEA-frame. Metal substituted as (a) single center, (b) two centers. Metal grafting: (c) M monomers, (d) dimeric complex $\mathrm{M}-\mathrm{O}_{\mathrm{b}}-\mathrm{M}$ in the BEA-pore, (e) nanoparticles inside pores and at the surface 


\subsection{Metal dimers stabilization in the BEA-framework}

The stabilization of dimeric $\mathrm{M}-\mathrm{O}_{\mathrm{b}}-\mathrm{M}$ complexes (where $\mathrm{M}=\mathrm{Sn}$ or $\mathrm{Fe}$ ) in the BEA pore and at the BEA surface (observed after the hierarchization of BEA zeolite in alkaline media), was investigated (Figure 5). Dimeric models used previously in studies of isocyanic acid adsorption were used. ${ }^{23}$ The stabilization energies are listed in Table 1.

Both Sn and Fe dimers have been stabilized above the Al-center in the BEA framework, near the neighboring oxygen atom, with an energy of approximately $-8 \mathrm{eV}$ inside the pore and $-7 \mathrm{eV}$ at the surface. The structure of the $\mathrm{M}-\mathrm{O}_{\mathrm{b}}-\mathrm{M}$ dimer does not depend on the cluster: dimers of each metal ( $\mathrm{Sn}$ or $\mathrm{Fe})$ have a similar structure in the 'ideal' $\left(\mathrm{Al}_{2} \mathrm{Si}_{22} \mathrm{O}_{64} \mathrm{H}_{32}\right)$ and 'hierarchical' $\left(\mathrm{Al}_{2} \mathrm{Si}_{12} \mathrm{O}_{39} \mathrm{H}_{22}\right)$ clusters. However, the differences in the geometry of the dimers for each of metals, Sn and Fe, are observed. The bond lengths between the tin centers and the bridging oxygen are approximately $2.0 \AA$, with bond orders of approximately 1.0 and 0.9 .
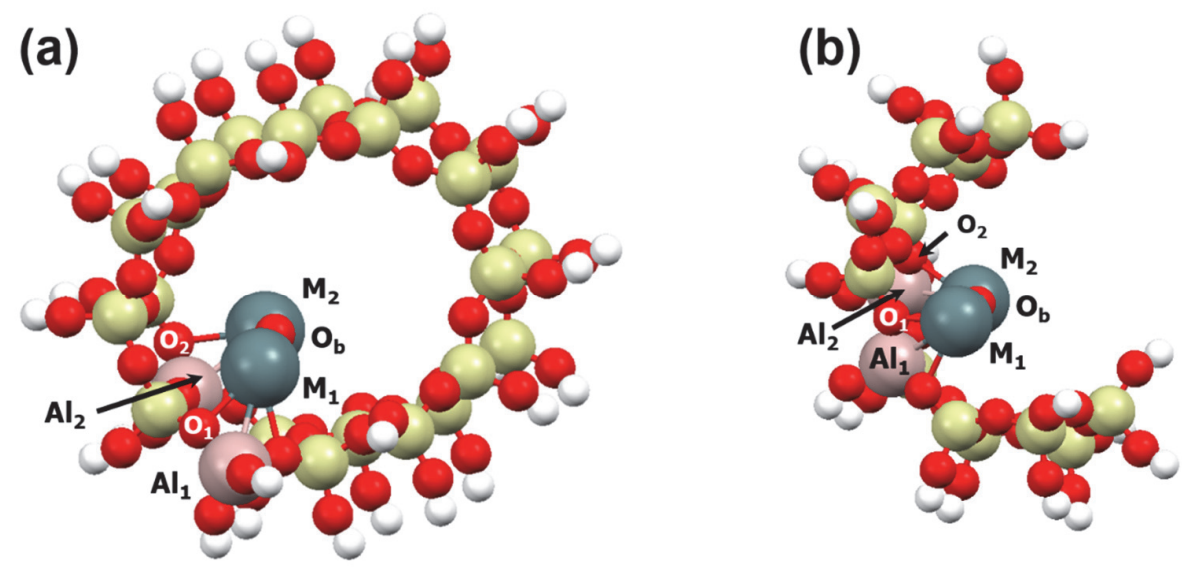

Fig. 5. Dimeric complex $\mathrm{M}-\mathrm{O}_{\mathrm{b}}-\mathrm{M}$ (where $\mathrm{M}=\mathrm{Sn}$ or $\mathrm{Fe}$ ) in the BEA: (a) ideal inside pore, (b) after hierarchization.

Table 1. Atomic charges, distances $(\AA)$ and bond orders (Mayer bond analysis) of iron and tin dimers stabilized in the (a) $\mathrm{M}_{2} \mathrm{Si}_{22} \mathrm{O}_{64} \mathrm{H}_{32}$ (ideal) and (b) $\mathrm{M}_{2} \mathrm{Si}_{12} \mathrm{O}_{39} \mathrm{H}_{22}$ (hierarchical) clusters

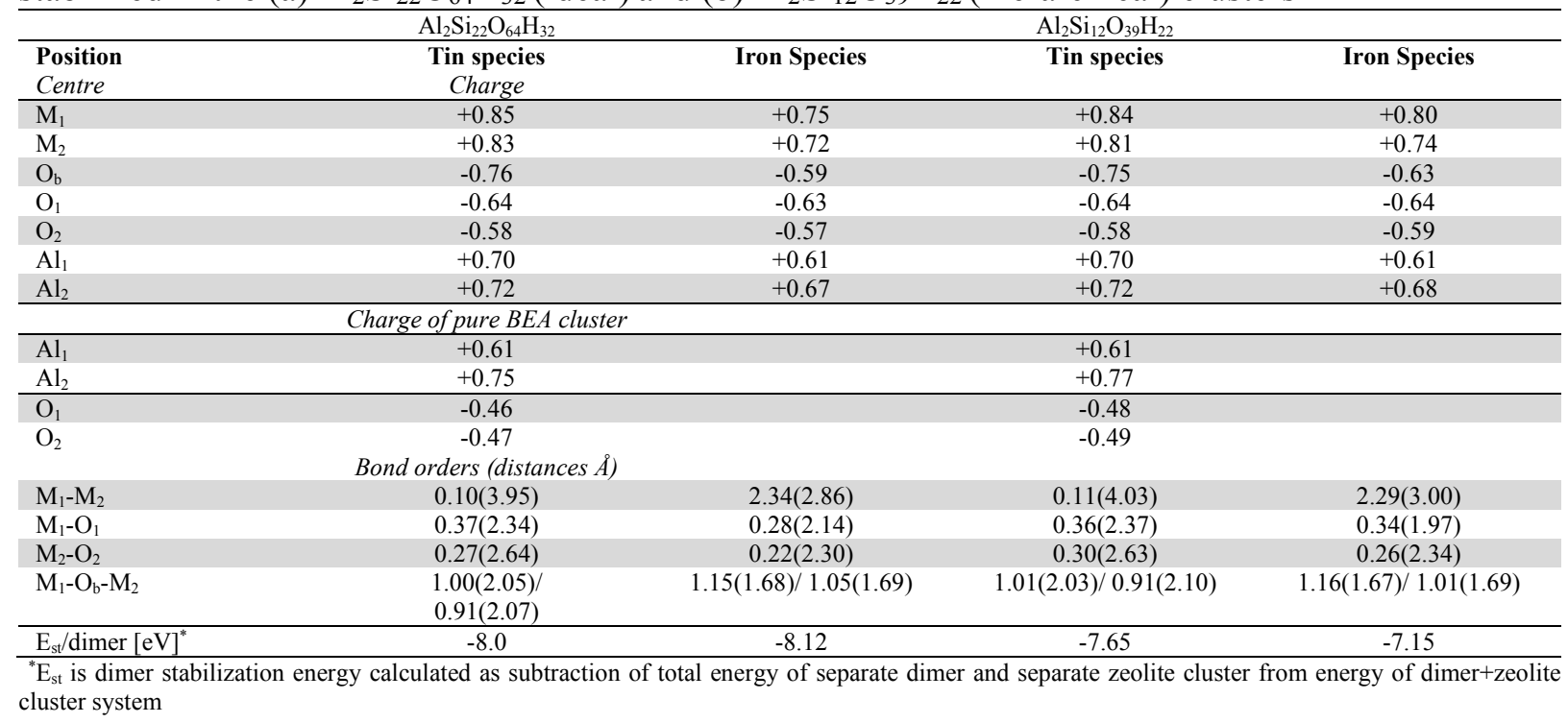


The bond lengths between the iron centers and bridging oxygen are approximately $1.68 \AA$, with a bond order of approximately 1.16 and 1.0. The strong coupling between iron centers has been noted (with a bond order of 2.3), while in case of tin, metal-metal interactions are negligible.

\subsection{Lactic acid dehydration over metal dimers in the BEA-framework}

The dehydration of lactic acid into acrylic acid requires the subtraction of hydrogen from the $\beta$-carbon (methyl group) and the hydroxyl group from the $\alpha$-carbon (Figure $6 a$ ). Lactic acid has three available atoms for adsorption above the catalyst surface: the oxygen atom of the hydroxyl group from $\alpha$-carbon and the two oxygen atoms of the carboxyl group.

(a)

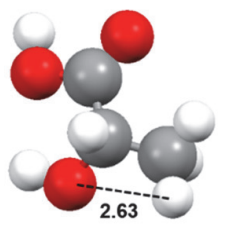

(e)

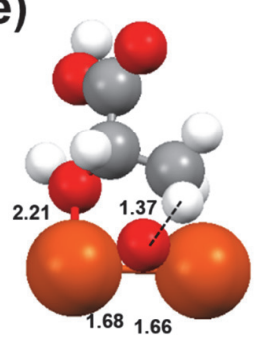

(b)

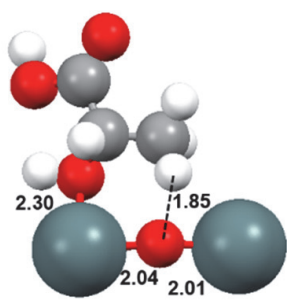

(f)

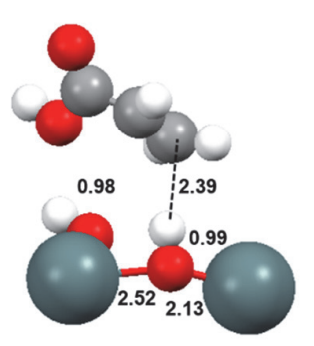

(c)

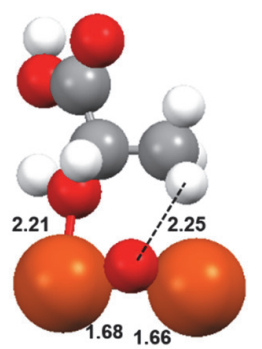

(g)

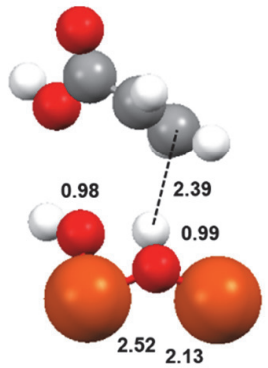

(d)

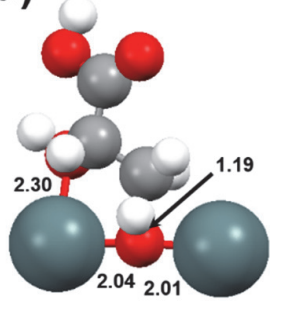

(h)

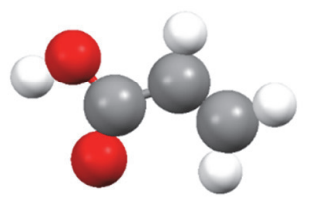

Fig. 6. Lactic (LA) and acrylic (AA) acid structures: (a) pure lactic acid, (b) LA optimized above Sndimer, (c) LA optimized above Fe-dimer for hierarchical model, (d) LA transition state above Sn-dimer, (e) LA transition state above Fe-dimer, (f) AA above Sn-dimer, (g) AA above Fe-dimer, (h) pure acrylic acid. The zeolite frame was removed in case of (b)- $(\mathrm{g})$ for better visualization of adsorbed species. For (b)-(g) see Figure $7 \mathrm{~b}$ for full structure of LA- and AA-metal dimer inside zeolite frame.

Based on the literature, ${ }^{25}$ lactic acid adsorption over zirconia oxide gives several possible binding modes: monodentate, bidentate bridging and bidentate chelating. Based on this literature result, we attempted to find a path of lactic acid dehydration inside the pure and metal substituted zeolite framework. Therefore, possible modes of interaction of lactic acid with different cations ( $\mathrm{Si}, \mathrm{Al}, \mathrm{Sn}$, $\mathrm{Fe}$ ) inside the zeolite framework have been considered. However, the lactic acid did not interact with the zeolite framework sites. Consequently, another direct pathway of lactic acid dehydration has been considered, which involves the simultaneous interaction of hydrogen from the $\beta$-carbon (methyl group) and the hydroxyl group from the $\alpha$-carbon. The possibility of direct lactic acid dehydration, reported in the literature, ${ }^{51}$ is the interaction of lactic acid with water, where water takes part in the transition state of the dehydration reaction by forming a six-member ring transition state (binding via the oxygen atom with the hydroxyl group from the LA- $\alpha$-carbon and via the hydroxyl group with the hydrogen from the LA- $\beta$-carbon). 
Table 2

Atomic charges, distances $(\AA)$ and bond orders (Mayer bond analysis) of lactic acid above iron and tin dimers stabilized in the (a) $\mathrm{M}_{2} \mathrm{Si}_{22} \mathrm{O}_{64} \mathrm{H}_{32}$ (ideal) and (b) $\mathrm{M}_{2} \mathrm{Si}_{12} \mathrm{O}_{39} \mathrm{H}_{22}$ (hierarchical) clusters after lactic acid adsorption.

\begin{tabular}{lcccc}
\hline & $\mathrm{Al}_{2} \mathrm{Si}_{22} \mathrm{O}_{64} \mathrm{H}_{32}$ & & $\mathrm{Al}_{2} \mathrm{Si}_{12} \mathrm{O}_{39} \mathrm{H}_{22}$ & \\
\hline Position & Tin species & Iron Species & Tin species & Iron Species \\
\hline Centre & Charge & & & 0.72 \\
\hline $\mathrm{M}_{1}$ & 0.75 & 0.71 & 0.74 & 0.81 \\
$\mathrm{M}_{2}$ & 0.72 & 0.82 & 0.73 & -0.65 \\
$\mathrm{O}_{\mathrm{b}}$ & -0.80 & -0.65 & -0.81 & -0.65 \\
$\mathrm{O}_{1}$ & -0.63 & -0.65 & -0.63 & -0.60 \\
$\mathrm{O}_{2}$ & -0.57 & -0.60 & -0.57 & 0.57 \\
$\mathrm{Al}_{1}$ & 0.71 & 0.56 & 0.71 & 0.64 \\
$\mathrm{Al}_{2}$ & 0.72 & 0.64 & 0.72 & \\
& Bond orders & & & $2.05(2.99)$ \\
$\mathrm{M}_{1}-\mathrm{M}_{2}$ & $($ distances $A)$ & & & $0.29(1.96)$ \\
$\mathrm{M}_{1}-\mathrm{O}_{1}$ & $0.10(4.04)$ & $2.07(2.99)$ & $0.10(4.04)$ & $0.19(2.25)$ \\
$\mathrm{M}_{2}-\mathrm{O}_{2}$ & $0.37(2.30)$ & $0.28(1.96)$ & $0.39(2.29)$ & $1.15(1.66) /$ \\
$\mathrm{M}_{1}-\mathrm{O}_{\mathrm{b}}-\mathrm{M}_{2}$ & $0.29(2.48)$ & $0.18(2.26)$ & $0.28(2.55)$ & $1.01(1.68)$ \\
& $1.02(1.99) /$ & $1.15(1.66) /$ & $1.00(2.01) /$ & $0.004(2.25)$ \\
$\mathrm{O}_{\mathrm{b}}-\mathrm{H}_{\mathrm{LA}}$ & $0.73(2.05)$ & $1.01(1.68)$ & $0.75(2.04)$ & $0.24(2.21)$ \\
$\mathrm{M}_{2}-\mathrm{OH}_{\mathrm{LA}}$ & $0.02(1.92)$ & $0.003(2.25)$ & $0.02(1.85)$ & -0.35 \\
$\Delta \mathrm{E}_{\mathrm{ad}}(\mathrm{LA})[\mathrm{eV}]$ & $0.29(2.39)$ & $0.26(2.22)$ & $0.32(2.30)$ & 1.99 \\
\hline
\end{tabular}

The metal dimers, discussed in paragraph 4.1 have similar potential for direct LA dehydration. Through the analysis of geometric compatibility, the metallic dimers, $\mathrm{M}-\mathrm{O}_{\mathrm{b}}-\mathrm{M}$, have been considered for the formation of the transition state between lactic and acrylic acid, based on previous studies of iron dimers inside ZSM-5. ${ }^{23}$ The adsorption of lactic acid has been investigated based on Sn- and FeBEA cluster models. Both metals have positive charges (between +0.7 and +0.85 , Table 1 ) and could easy interact with the $\mathrm{OH}$ group of lactic acid. The structures of lactic acid, adsorbed at the $\mathrm{M}-\mathrm{O}_{\mathrm{B}}-\mathrm{M}$ dimer inside BEA, are shown in Figure $6 \mathrm{~b}$ and c. The distance between the oxygen center of the LA$\alpha$-carbon hydroxyl group and the LA- $\beta$-carbon hydrogen is $2.63 \AA$, which is favourable in terms of the geometrical compatibility with the $\mathrm{M}-\mathrm{O}$ distance, which equals 2.04 and $1.68 \AA$ for $\mathrm{Sn}$ and $\mathrm{Fe}$, respectively. The distance between the LA- $\beta$-carbon hydrogen and the bridge oxygen of $\mathrm{M}-\mathrm{O}_{\mathrm{b}}-\mathrm{M}$ dimer is still too long to allow for hydrogen subtraction from LA and hydroxyl group formation.

Table 2 presents the changes in the electronic properties of the metal dimer: the bridge oxygen starts interacts weakly with the LA- $\beta$-carbon hydrogen. Therefore, in the second step the transition state is considered (Figure $6 \mathrm{~d}$ and e), where the adsorbed LA molecule rotates and the LA- $\beta$-carbon hydrogen bond is shortened to approximately 1.19 and $1.37 \AA$. The metal center binds with the hydroxyl group from the LA- $\alpha$-carbon and the bridge oxygen with hydrogen from the LA- $\beta$-carbon.

Figure 7 shows the energy diagram of the dehydration of lactic acid into acrylic acid over dimeric metal complexes inside an ideal pore based on a hierarchical model of BEA zeolite. The adsorption of lactic acid is endothermic in the case of Sn-BEA (3.18 and 1.99eV for the 'ideal' and 'hierarchical' model, respectively, Figure 7 (2) and Table 2), is slightly endothermic in the case of 'ideal' Fe-BEA $(0.26 \mathrm{eV}$, Figure $\left.7 \mathrm{a},\left(2^{\prime}\right)\right)$ and exothermic $\left(-0.35 \mathrm{eV}\right.$, Figure $\left.6 \mathrm{~b},\left(2^{\prime}\right)\right)$ in the case of a hierarchical Fe-BEA catalyst. The dehydration of lactic acid into acrylic acid proceeds with an energy barrier of 2.4 and $3.6 \mathrm{eV}$ for Sn-BEA (Figure 7, (3)) and 3.1 and 4eV for Fe-BEA (Figure 7, (3')). However, the energy level of acrylic acid above Fe-BEA has been found to be lower than the energy level of lactic acid $(-0.38 \mathrm{eV}$ for 
the 'ideal' model and $-0.8 \mathrm{eV}$ for the 'hierarchical' model, Figure 7 (4') and Table 3). After acrylic acid desorption, two strong $\mathrm{OH}$ groups remained at the $\mathrm{M}-\mathrm{O}_{\mathrm{b}}-\mathrm{M}$ dimer (see Table 3 ).

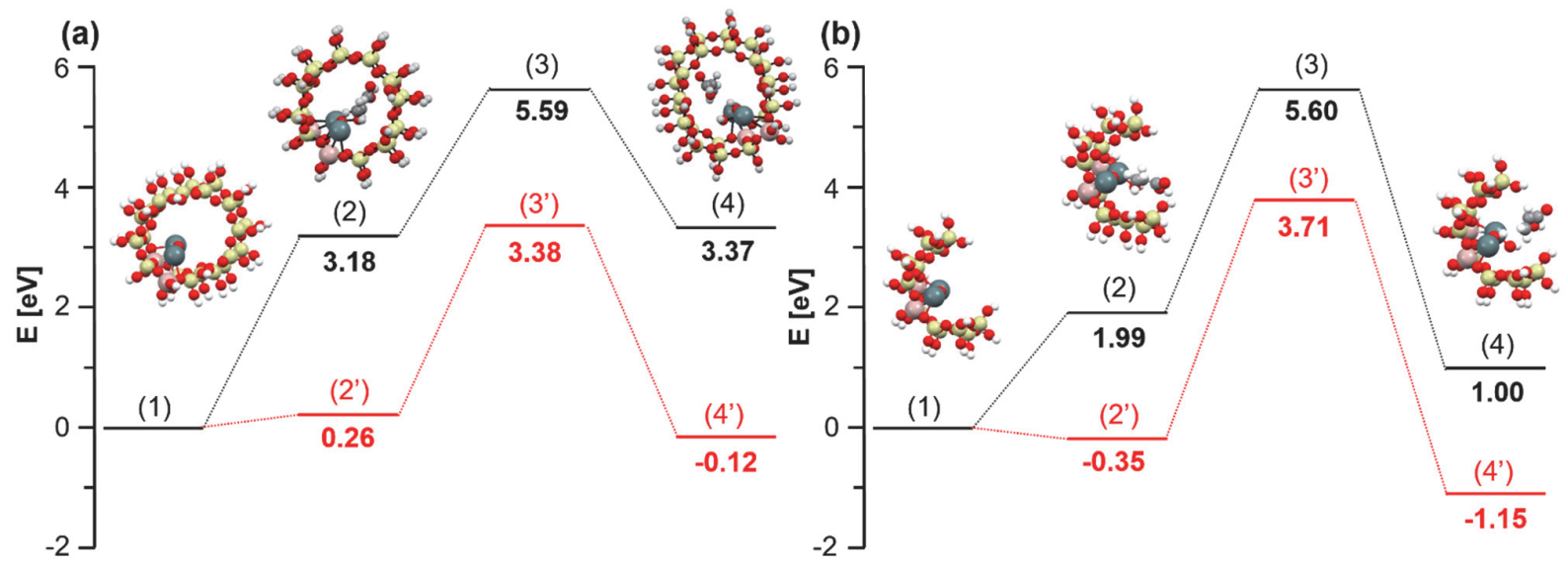

Fig. 7. Energy diagram of lactic acid dehydration into acrylic acid over dimeric M-O-M complex in the BEA zeolite, where $\mathrm{M}=\mathrm{Sn}$ (black) or $\mathrm{Fe}$ (red): (a) inside pore, ideal structure, (b) at hierarchical model. Energy level of (1) M-O $\mathrm{b}_{-} \mathrm{M}$ dimer, (2) and (2') lactic acid adsorption, (3) and (3') transition state, (4) and (4') acrylic acid desorption over Sn- and Fe dimer, respectively

\section{Table 3}

Atomic charges, distances $(\AA)$ and bond orders (Mayer bond analysis) of lactic acid above iron and tin dimers stabilized in the (a) $\mathrm{M}_{2} \mathrm{Si}_{22} \mathrm{O}_{64} \mathrm{H}_{32}$ (ideal) and (b) $\mathrm{M}_{2} \mathrm{Si}_{12} \mathrm{O}_{39} \mathrm{H}_{22}$ (hierarchical) clusters after acrylic acid desorption.

\begin{tabular}{|c|c|c|c|c|}
\hline & $\mathrm{Al}_{2} \mathrm{Si}_{22} \mathrm{O}_{64} \mathrm{H}_{32}$ & & $\mathrm{Al}_{2} \mathrm{Si}_{12} \mathrm{O}_{39} \mathrm{H}_{22}$ & \\
\hline Position & Tin species & Iron Species & Tin species & Iron Species \\
\hline Centre & Charge & & & \\
\hline $\mathrm{M}_{1}$ & 0.85 & 0.77 & 0.84 & 0.74 \\
\hline $\mathrm{M}_{2}$ & 0.83 & 0.83 & 0.82 & 0.82 \\
\hline $\mathrm{O}_{\mathrm{b}}$ & -0.84 & -0.86 & -0.83 & -0.85 \\
\hline $\mathrm{O}_{1}$ & -0.64 & -0.64 & -0.64 & -0.64 \\
\hline $\mathrm{O}_{2}$ & -0.60 & -0.60 & -0.60 & -0.59 \\
\hline $\mathrm{Al}_{1}$ & 0.68 & 0.58 & 0.68 & 0.67 \\
\hline \multirow[t]{2}{*}{$\mathrm{Al}_{2}$} & 0.72 & 0.67 & 0.72 & 0.60 \\
\hline & $\begin{array}{l}\text { Bond orders } \\
\text { (distances A) }\end{array}$ & & & \\
\hline $\mathrm{M}_{1}-\mathrm{M}_{2}$ & $0.05(4.55)$ & $0.67(3.29)$ & $0.05(4.55)$ & $0.71(3.29)$ \\
\hline $\mathrm{M}_{1}-\mathrm{O}_{1}$ & $0.41(2.36)$ & $0.39(1.98)$ & $0.42(2.36)$ & $0.39(2.02)$ \\
\hline $\mathrm{M}_{2}-\mathrm{O}_{2}$ & $0.27(2.70)$ & $0.25(2.33)$ & $0.28(2.70)$ & $0.26(2.29)$ \\
\hline $\mathrm{M}_{1}-\mathrm{O}_{\mathrm{b}}-\mathrm{M}_{2}$ & $\begin{array}{c}0.83(2.13) / 0.27 \\
(2.52)\end{array}$ & $\begin{array}{c}0.69(1.87) / 0.57 \\
(1.88)\end{array}$ & $\begin{array}{c}0.82(2.13) / 0.27 \\
(2.52)\end{array}$ & $\begin{array}{c}0.71(1.83) / 0.55 \\
(1.91)\end{array}$ \\
\hline $\mathrm{O}_{\mathrm{b}}-\mathrm{H}_{\mathrm{LA}}$ & $0.64(0.99)$ & $0.59(1.00)$ & $0.66(0.99)$ & $0.61(0.99)$ \\
\hline $\mathrm{M}_{2}-\mathrm{OH}_{\mathrm{LA}}$ & $0.97(2.09)$ & $1.11(1.76)$ & $0.97(2.09)$ & $1.08(1.81)$ \\
\hline$\Delta \mathrm{E}_{\mathrm{des}}(\mathrm{AA})[\mathrm{eV}]$ & 0.19 & -0.38 & -0.99 & -0.80 \\
\hline
\end{tabular}

In summary, from an energetics point of view, the hierarchical Fe-BEA zeolite has the best catalytic properties for the direct dehydration of lactic acid into acrylic acid. A similar reaction mechanism is also expected at the polymeric metal species, where the bridge oxygen is present. As the next step is 
investigated, a catalyst will be theoretically synthesized and tested for lactic acid dehydration in our laboratory.

\section{Conclusions}

The ideal and hierarchical structure of BEA zeolite has been considered: the 'ideal' model describes an ideal structure, while the 'hierarchical' model indicates a zeolite structure after hierarchization. The metal $\mathrm{M}-\mathrm{O}_{\mathrm{b}}-\mathrm{M}$ dimers have been found to be stable above oxygen bound with aluminium centers of BEA zeolite with an energy barrier above $-8 \mathrm{eV}$ inside pores and $-7 \mathrm{eV}$ at the surface model. The mechanism of direct lactic acid dehydration in Sn- and Fe-BEA zeolite, which are both ideal and after hierarchization, has been found. The geometric compatibility of the metallic dimers and lactic acid allows for the proposed direct dehydration mechanism, where the oxygen center of the hydroxyl group of the LA- $\alpha$-carbon interacts with the metal center of the dimer and hydrogen is subtracted from the LA- $\beta$-carbon and bound with the bridge oxygen of the metal dimer. The adsorption of lactic acid is endothermic in the case of Sn-BEA, slightly endothermic in ideal Fe-BEA and exothermic in the case of a hierarchical Fe-BEA catalyst. The dehydration of lactic acid into acrylic acid proceeds with an energy barrier of 2.4 and $3.6 \mathrm{eV}$ for Sn-BEA and 3.1 and $4 \mathrm{eV}$ for Fe-BEA. However, the energy level of acrylic acid above Fe-BEA has been found to be lower than the energy level of lactic acid (-0.38eV for the 'pore' model and $-0.8 \mathrm{eV}$ for the 'surface' model). The hierarchical Fe-BEA zeolite has been theoretically found to be the best catalyst for the direct dehydration of lactic acid into acrylic acid.

\section{Acknowledgements}

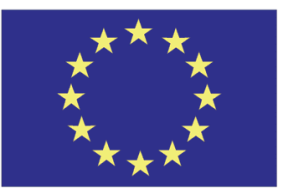

This project has received funding from the European Union's Horizon 2020 research and innovation programme under the Marie Skłodowska-Curie grant agreement No. 665778 (Polonez-1 no. 2015/19/P/ST4/02482 of National Science Centre, Poland). This work was supported in part by the PL-Grid Infrastructure.

\section{References}

1 Corma A., Iborra S., \& Velty A. (2007). Chemical Routes for the Transformation of Biomass into Chemicals, Chem. Rev., 107, 2411-2502.

2 Rinaldi R., \& Schüth F. (2009). Design of solid catalysts for the conversion of biomass, Energy Environ. Sci., 2, 610-626.

3 Stöcker M. (2008). Biofuels and biomass-to-liquid fuels in the biorefinery: catalytic conversion of lignocellulosic biomass using porous materials, Angew Chem Int Ed Eng., 47, 9200-11.

4 Montejo-Valencia B. D., Salcedo-Pérez, J. L., \& Curet-Arana, M. C. J. (2016). DFT Study of Closed and Open Sites of BEA, FAU, MFI, and BEC Zeolites Substituted with Tin and Titanium, J. Phys. Chem. C, 120, 2176-2186.

5 Osmundsen C. M., Holm M. S., Dahl S., \& Taarning, E. (2012). Tin-containing silicates: structureactivity relations, Proc. R. Soc. London, Ser. A, 468, 2000-2016.

6 Wolf P., Valla M., Rossini A. J., Comas-Vives A., Núñez-Zarur F., Malaman B., Lesage A., Emsley L., Copéret C., \& Hermans I., (2014). NMR signatures of the active sites in Sn- $\beta$ zeolite, Angew Chem Int Ed Eng., 53,10179-83.

7 Corma A., Domine M. E., Nemeth L., \& Valencia S. (2002). Al-Free Sn-Beta Zeolite as a Catalyst for the Selective Reduction of Carbonyl Compounds (Meerwein-Ponndorf-Verley Reaction), $J$. Am. Chem. Soc., 124, 3194-3195.

8 Lew C. M., Rajabbeigi N., \& Tsapatsis M. (2012). Tin-containing zeolite for the isomerization of cellulosic sugars, Microporous and Mesoporous Materials, 153, 55-58. 
9 Yang G., Pidko E., \& Hensen E. J. M. (2013). Structure, Stability, and Lewis Acidity of Mono and Double Ti, Zr, and Sn Framework Substitutions in BEA Zeolites: A Periodic Density Functional Theory Study, J. Phys. Chem. C, 117, 3976-3986.

10 Boronat M., Concepcion P., Corma A., Renz M., \& Valencia S. (2005). Determination of the catalytically active oxidation Lewis acid sites in Sn-beta zeolites, and their optimisation by the combination of theoretical and experimental studies. J. Catal., 234, 111-118.

11 Sun Q., Gao Z.X., Chen H.Y., \& Sachtler W. (2001) Reduction of NOx with Ammonia over Fe/MFI: Reaction Mechanism Based on Isotopic Labeling. Journal of Catalysis, 201, 89-99.

12 Heindrich F., Schmidt C., Loeffler E., Menzel M., \& Gruenert W. (2002). Fe-ZSM-5 Catalysts for the Selective Reduction of NO by Isobutane-The Problem of the Active Sites, J. Catalysis, 212, 157-172.

13 Kröcher O., Devadas M., Elsener M., Wokaun A., Soger N., Pfeifer M., Demel Y., \& Mussmann L. (2006) Influence of $\mathrm{NO}_{2}$ on the selective catalytic reduction of $\mathrm{NO}$ with ammonia over Fe-ZSM5, Appl. Catalysis B: Environmental, 67, 187-196.

14 Boroń P., Rutkowska M., Gil B., Marszałek B., Chmielarz L., \& Dzwigaj S. (2019). Experimental Evidence of the Mechanism of Selective Catalytic Reduction of NO with NH3 over Fe-Containing BEA Zeolites, ChemSusChem 12, 692-705.

15 Schwidder M., Grünert W., Bentrup U., \& Brückner A. (2006). Selective reduction of NO with FeZSM-5 catalysts of low Fe content: Part II. Assessing the function of different Fe sites by spectroscopic in situ studies, J. Catalysis, 239, 173-186.

16 Heinrich F., Schmidt C., Löffler E., Menzel M., \& Grünert W. (2002). Fe-ZSM-5 catalysts for the selective reduction of NO by isobutane - The problem of the active sites, J. Catalysis, 212, 157-172.

17 Rivallan M., Ricchiardi G., Bordiga S., Zecchina A. (2009). Adsorption and reactivity of nitrogen oxides $\left(\mathrm{NO}_{2}, \mathrm{NO}, \mathrm{N}_{2} \mathrm{O}\right)$ on Fe-zeolites, J. Catalysis, 264, 104-116.

18 Pirutko L.V., Chernyavsky V.S., Starokon E.V., Ivanov A.A., Kharitonov A.S., \& Panov G.I. (2009). The role of $\alpha$-sites in N2O decomposition over FeZSM-5. Comparison with the oxidation of benzene to phenol, Applied Catalysis B: Environmental, 91, 174-179.

19 Fellah M.F., van Santen R.A., \& Onal, I. (2009). Oxidation of benzene to phenol by $\mathrm{N}_{2} \mathrm{O}$ on an $\mathrm{Fe}^{2+}$-ZSM-5 cluster: A density functional theory study, J. Physical Chemistry C, 113, 15307-15313.

20 Yuranov I., Bulushev D.A., Renken A., \& Kiwi-Minsker, L. (2007). Benzene to phenol hydroxylation with N2O over Fe-Beta and Fe-ZSM-5: Comparison of activity per Fe-site. Applied Catalysis A: General, 319, 128-136.

21 Ivanov D.P., Piryutko L.V., \& Sobolev, V.I. (2004). Biphenyl oxidation with nitrous oxide on MFI zeolites. Petroleum Chemistry, 44, 322-327.

22 Ehrich H., Schwieger W., Jahnisch K. (2004). Investigations on the selective oxidation of benzonitrile using nitrous oxide catalyzed by modified ZSM-5 zeolites, Applied Catalysis A: General, 272, 311-319.

23 Czekaj I., Brandenberger S., \& Kröcher, O. (2013) Theoretical studies of HNCO adsorption at stabilized iron complexes in the ZSM-5 framework, Microporous Mesoporous Materials, 169, 97102.

24 Chen B., Liu N., Liu X., Zhang R., Li Y., Li Y., \& Sun, X. (2011) Study on the direct decomposition of nitrous oxide over Fe-beta zeolites: From experiment to theory, Catalysis Today, 175, 245-255.

25 Dai, C., Lei, Z., Wang, Y., Zhang, R., \& Chen, B. (2013). Reduction of N2O by CO over Fe- and Cu-BEA zeolites: An experimental and computational study of the mechanism, Microporous and Mesoporous Materials, 167, 254-266.

26 Battiston A.A., Bitter J.H., \& Koningsberger D.C. (2003). Reactivity of binuclear Fe complexes in over-exchanged Fe/ZSM5, studied by in situ XAFS spectroscopy 2. Selective catalytic reduction of NO with isobutane, J. Catalysis, 218, 163-177.

27 Chen H.Y., \& Sachtler W.M.H. (1998). Activity and durability of Fe/ZSM-5 catalysts for lean burn NOx reduction in the presence of water vapor, Catalysis Today, 42, 73-83.

28 Joyner R., Stockenhuber M. (1999). Preparation, Characterization, and Performance of Fe-ZSM-5 Catalysts, J. Phys. Chem. B, 103, 5963-5976. 
29 Joyner R.W., \& Stockenhuber M. (1997). Unusual structure and stability of iron-oxygen nanoclusters in Fe-ZSM-5 catalysts. Catalysis Letters, 45, 15-19.

30 Schwidder M., Kumar M.S., Klementiev K., Pohl M.M., Brückner A., \& Grünert, W. (2005). Selective reduction of NO with Fe-ZSM-5 catalysts of low Fe content: I. Relations between active site structure and catalytic performance, J. Catalysis, 231, 314-330.

31 Krishna K., \& Makkee M. (2006). Preparation of Fe-ZSM-5 with enhanced activity and stability for SCR of NOx. Catalysis Today, 114, 23-30.

32 Hensen E.J.M., Zhu Q., \& van Santen R.A. (2003). Extraframework Fe-Al-O species occluded in MFI zeolite as the active species in the oxidation of benzene to phenol with nitrous oxide, $J$. Catalysis, 220, 260-264.

33 Zecchina A., Rivallan M., Berlier G., Lamberti C., \& Ricchiardi, G. (2007). Structure and nuclearity of active sites in Fe-zeolites: comparison with iron sites in enzymes and homogeneous catalysts, Phys. Chem. Chem. Phys., 9, 3483-99.

34 Sun K., Xia H., Feng Z., van Santen R., Hensen E., \& Li C. (2008). Active sites in Fe/ZSM-5 for nitrous oxide decomposition and benzene hydroxylation with nitrous oxide, J. Catal., 254, 383-396.

35 Panov G.I., Uriarte A.K., Rodkin M.A., \& Sobolev V.I. (1998). Generation of active oxygen species on solid surfaces. Opportunity for novel oxidation technologies over zeolites, Catal. Today, 41, 365385.

36 El-Malki E.M., van Santen R.A., \& Sachtler W.M.H. (2000). Active Sites in Fe/MFI Catalysts for NOx Reduction and Oscillating N2O Decomposition, J. Catal., 196, 212-223.

37 Perez-Ramirez J. (2004). Active iron sites associated with the reaction mechanism of $\mathrm{N}_{2} \mathrm{O}$ conversions over steam-activated FeMFI zeolites, J. Catal., 227, 512-522.

38 Pirngruber G.D., \& Roy P.K. (2005). A look into the surface chemistry of $\mathrm{N}_{2} \mathrm{O}$ decomposition on iron zeolites by transient response experiments, Catal. Today, 110, 199-210.

39 Hammaecher C., Paul J.-F. (2013) Density functional theory study of lactic acid adsorption and dehydration reaction on monoclinic 011,101 , and 111 zirconia surfaces, J. Catal., 300, 174-182.

40 Hermann K., Pettersson L. G. M., Casida M. E., Daul C., Goursot A., Koester A., Proynov E., StAmant A., Salahub D. R., Carravetta V., Duarte A., Godbout N., Guan J., Jamorski, C., Leboeuf M., Leetmaa M., Nyberg M., Pedocchi L., Sim F., Triguero L., \& Vela A. (2005). StoBe-deMon, deMon Software: Stockholm, Berlin.

41 Perdew J. P., Burke K., \& Ernzerhof M. (1996). Generalized gradient approximation made simple. Phys. Rev. Lett., 77, 3865-3868.

42 Hammer B., Hansen L. B., \& Nørskov J. K. (1999). Improved Adsorption Energetics within DensityFunctional Theory using Revised Perdew-Burke-Ernzerhof Functionals. Phys. Rev. B, 59, 7413-7421.

43 Labanowski J. K., \& Anzelm J. W., Eds. (1991). Density Functional Methods in Chemistry. Springer-Verlag: New York.

44 Jasiński R., Demchuk O.M., \& Babyuk D. (2017). A Quantum-Chemical DFT Approach to Elucidation of the Chirality Transfer Mechanism of the Enantioselective Suzuki-Miyaura CrossCoupling Reaction. Journal of Chemistry, 2017, 3617527.

45 Mulliken R. S. (1955). Electronic Population Analysis on LCAO-MO Molecular Wave Functions. J. Chem. Phys., 23, 1833-1845.

46 Mayer I. (1983) Charge, Bond Order and Valence in the ab initio SCF Theory, Chem. Phys. Lett., 97, 270-274.

47 Mayer I. (1987). Bond Orders and Valences: Role of d-Orbitals for Hypervalent Sulphur. J. Mol. Struct. (THEOCHEM), 149, 81-89.

48 Database of Zeolite Structure, International Zeolite Association (IZA), http://www.izastructure.org/databases/.

49 Szostak R., Pan J. M., \& Lillerud K. P. (1995). High-resolution TEM imaging of extreme faulting in natural zeolite tschernichite, J. Phys. Chem., 99, 2104-2109.

50 First E. L., Gounaris C. E., Wei J., \& Floudas C. A. (2011). Computational characterization of zeolite porous networks: an automated approach, Phys. Chem. Chem. Phys., 13, 17339-17358. 
51 Aida T.M., Ikarashi A., Saito Y., Watanabe M., Smith Jr. R.L., \& Arai, K. (2009). Dehydration of lactic acid to acrylic acid in high temperature water at high pressures, J. of Supercritical Fluids, 50, 257-264.

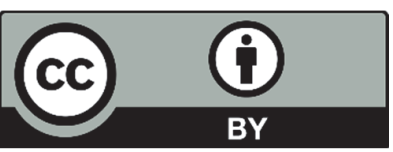

(C) 2019 by the authors; licensee Growing Science, Canada. This is an open access article distributed under the terms and conditions of the Creative Commons Attribution (CC-BY) license (http://creativecommons.org/licenses/by/4.0/). 